\title{
ASPECTOS CREATIVOS DE LA OBRA DE GUSTAVE DORE
}

\section{Juan Rodrigo Lobato Castaño}




\title{
ASPECTOS CREATIVOS DE
}

\author{
LA OBRA DE
}

\section{GUSTAVE DORÉ}

Juan Rodrigo Lobato Castaño

Este artículo se va a centrar en los aspectos creativos y heurísticos (arte de crear) de la obra ilustrada de Paul Gustave Doré. Para ello, vamos a buscar los elementos que definen la esencia de la creatividad y aplicarlos a la obra de este artista francés del siglo XIX, quien a pesar de poseer una de las obras que mayor difusión tiene en la historia de la humanidad, se presenta como un desconocido para la sociedad.

Numerosas, han sido las publicaciones sobre creatividad y heurística, $\mathrm{y}$, si algo hay claro, es la enorme cantidad de conceptos que se han usado para apreciar cómo y qué hace que una persona o un objeto, obra, trabajo, etc. sea creativo. De este modo, conceptos como fluidez, flexibilidad, elaboración, coherencia interna, adecuación, así como, la experiencia profesional han sido muy citados por los autores, junto con los de originalidad, imaginación, invención y muchos más.

La creatividad, ha sido entendida como algo diferente a la inteligencia; aunque muchos autores consideran que radica en ella, ha sido objeto de estudio en múltiples investigaciones de muy diferente ámbito, tanto desde el 
artístico, del publicitario, del educativo, etc. Por tanto, dicho concepto es una característica propia del ser humano, que le atribuye una especie de don, tal y como ha prevalecido durante siglos, rayando con el concepto de genio, y que remarcaría el carácter absolutamente excepcional de esa persona.

Por lo general, sendos términos: genio y creatividad, han aparecido vinculados al surgimiento de nuevas obras de arte. Así, la actividad que distingue al genio es la creatividad. ${ }^{l}$

La creatividad surge del inconformismo, de la curiosidad; el creador debe tener un profundo conocimiento del campo en el que pretende innovar. Así, las personas creativas gozan de una gran inventiva, audacia, imaginación, etc. en contraposición a las que carecen de ella, que presentan apatía, conformismo y trivialidad.

Como aludimos anteriormente, algunos autores consideran que la creatividad reside en el intelecto de las personas, en cambio, otros consideran que se sitúa en la personalidad, y finalmente, los que ofrecen una explicación mixta entre ambos presupuestos, es decir, una mezcla de inteligencia y personalidad.

Analizar las características de un trabajo, de una obra, y considerar si es o no, un trabajo creativo es una tarea ardua, puesto que depende fundamentalmente de una serie de conceptos que denotan originalidad y diferencia. En este sentido, se hace necesaria una serie de consideraciones de carácter tanto cuantitativo como cualitativo.

En lo que concierne al aspecto cuantitativo referirse al volumen de producción, a la capacidad creadora; en lo que atañe al aspecto cualitativo, requiere de una consideración más subjetiva, la cual, valorará dicho fruto, es decir, la obra realizada.

\footnotetext{
${ }^{1}$ ESTRADA, D.: Estetica. Herder, Barcelona, 1988.
} 
Siguiendo la definición general de creatividad: Creatividad es la capacidad para engendrar algo nuevo, ya sea un producto, una técnica, un modo de enfocar la realidad... La creatividad impulsa a salirse de los cauces trillados, a romper las convenciones, las ideas estereotipadas, los modos generalizados de pensar y actuar.

Para Gulford, la creatividad, se reduce a aspectos como la capacidad para crear ingentes volúmenes de ideas, la capacidad de pasar de un aspecto a otro rápidamente o la capacidad de crear soluciones diferentes. Así, considera como ha hecho Miguel Baños ${ }^{2}$, aspectos como la fluidez, la flexibilidad o la originalidad.

Otros autores se han centrado en los aspectos cognoscitivos analizando el modo de pensamiento y observando si es un pensamiento divergente o convergente. En este sentido, el pensamiento divergente, por su enorme poder asociativo parece fundamentar la creatividad. En cambio, el pensamiento convergente es más propio del razonamiento, de la lógica, es decir, de la inteligencia, aunque creatividad e inteligencia van por decirlo así, cogidas de la mano.

Preguntarse por la naturaleza de la creatividad es algo bastante complicado, que durante mucho tiempo ha sido rebatido e investigado, pero muchos autores han considerado que para averiguar si un perfil es verdaderamente creativo, se hace necesaria una investigación biográfica. Así, dicho método, ha sido por decirlo así, el padre de disciplinas como la Historia del Arte, puesto que el primer método científico desarrollado en este área como ciencia moderna, vino dado por Vasari, recibiendo el nombre de método biográfico o vasariano. En este sentido, el estudio de las vidas permite apreciar con mejor perspectiva las actitudes que justificaron dichas habilidades propias de una mente creativa.

\footnotetext{
${ }^{2}$ BAÑOS GONZALEZ, M.: Métodos Heurísticos y Creación Publicitaria (Tesis doctoral, dirigida por el Dr. D. Francisco García García). Universidad Complutense de Madrid, Madrid, 1999.
} 
El concepto de estética es otro de los elementos que nos va a permitir apreciar el modo de entender y organizar su experiencia, así como el modo de expresarla, dotándola de forma y sentido. De este modo, el producto final se verá condicionado por aspectos que se presentan por lo general bellos, con capacidad para la conmoción y la sorpresa.

La creatividad como objeto de estudio puede ser investigada desde diferentes aspectos: el proceso de creación, el producto en sí, la personalidad del creador y el ambiente de creación, el entorno, es decir, el contexto sociohistórico.

El Arte es experiencia creativa en grado sumo, hay que referir que el sonido ( $r t$ ) proviene del sánscrito, de ahí evoluciona el termino arte. Dicho sonido aludía al proceso mismo de creación, era acto creador en sí, es apreciable la influencia oriental de la vibración del sonido que es esencia misma de la creación, del surgimiento de algo de la nada. Así, se vincula el concepto arte con el de creación, y esto desde el principio, desde el origen de los tiempos.

El verbo crear hasta el Renacimiento fue considerado desde una perspectiva teológica, relacionada con una actitud sobrenatural y divina de la cual había surgido la nada. Así el hombre al estar en un escalón inferior a Dios y a la Naturaleza podría hacer cosas, pero no crearlas. Este planteamiento persistiría durante el siglo XVIII, siendo mantenido por autores como Escoto o Ockham. No obstante, en el Renacimiento se consideró la cercanía del acto creativo con el acto de creación divino. De este modo, para los humanistas ingleses, el artista era semejante a Dios, ya que si Éste crea la Naturaleza, el hombre por imitación crearía una segunda naturaleza, la cual participaría de las leyes que rigen la obra creada por Dios. Así todos los conceptos aún están cercanos al de mimesis. Pero poco a poco, se va dirigiendo primero hacia el terreno de lo poético y lo imaginario como considera E. Young: En el reino de 
hadas de la fantasía, el genio puede vagar libremente; alli tiene poder creador y puede reinar a su albedrío sobre su propio imperio de quimeras. ${ }^{3}$

El autor, objeto de estudio, Gustave Doré (1832-1883), vivió el pleno apogeo del Romanticismo, durante estos momentos, el concepto de creatividad estaba siendo reconvertido y empezaba a tener unos tintes puramente filosóficos, llegándose incluso a sistematizar en una especie de Teoría de la Creatividad artística. En este sentido, el segundo mundo, el mundo del Arte se justificaba gracias a los mundos infinitos de Leibniz y al principio de actualización de estos mundos, y esto era conseguido gracias a la figura del genio, quien poseía la capacidad de penetrar en estos mundos y captar su esencia transportándola hasta nosotros. Pero sería con Kant con quien los planteamientos sobre el acto creador lleguen a lo más alto. No obstante Kant, parte de Fitche, quien considera al yo creador como voluntad, como imaginación, sentimiento inconsciente, muy cercano al propio concepto de Dios. En cambio Kant considera que el proceso venía determinado por un demiurgo quien ofrecía tanto el material como imponía sus limitaciones ${ }^{4}$.

Es apreciable la evolución hacia el idealismo, donde la imaginación y el inconsciente van a desempeñar papeles fundamentales en el proceso de creación, ya que justifica el alejamiento de unas normas para crear, otras regidas por el sujeto y no por la naturaleza, siendo éste quien ordena un mundo, el fantástico y originario con capacidad para expresar otras reglas, otros ordenes y generar nuevas experiencias capaces de expresar nuevos sentimientos y emociones verdaderas, pero limitadas hasta el momento por el uso restringido del acto creador.

Al cobrar protagonismo el inconsciente en la creatividad artística, empezarán a tener relevancia los sueños como propiciadores de la génesis de la obra. Esto se aprecia destacadamente desde los inicios del Romanticismo hasta la actualidad, acentuándose en sus postrimeras, así como en los estilos o

\footnotetext{
${ }^{3}$ Citado en ESTRADA, D.: Op Cit.

${ }^{4}$ Ibidem.
} 
movimientos que le suceden, fundamentalmente el Simbolismo, antecedente directo en este sentido del Surrealismo, en su vertiente onírica.

Como afirma Estrada, desde el siglo XVIII se pasa del mimetismo del mundo empírico, de la realidad, al mimetismo del mundo onírico. El artista niega la realidad y se deja seducir por la fantasía y el sueño, creando mundos cargados de un halo de misterio y fascinación que absorbe y transporta al espectador hacia universos extraños que exploran paisajes interiores propiciados por el inconsciente.

El sueño recubre la obra de una extraordinaria carga poética que transforma la realidad en un extrañamiento cargado de belleza y sorpresa, liberando las ataduras del creador y ofreciendo un repertorio de visiones para el espectador que podrían mostrar como considera Novallis una realidad invisible, dirigiéndonos hacia un nivel de consciencia superior.

Hemos aludido a algunas cuestiones, conceptos y autores que se han referido a cuestiones concernientes a nuestro tema, sin embargo, se hace necesaria una pequeña enumeración que recopile los aspectos que definen la creatividad. Así, cabe preguntarse ¿Qué fundamenta la naturaleza de la creatividad?.

Como hemos ido refiriendo, han sido muchos los autores que sobre esta cuestión han arrojado luces sobre este sombrío terreno dirigiéndose hacia las actitudes que definen la mente creativa, así como el proceso y métodos de ser creativos, fundamentando estas cuestiones que la creatividad es susceptible de ser aprendida, si no bien de ser encajonada y enmarcada con unos límites que definan el cómo hacer, el cómo pensar o qué métodos usar para ser más y más creativo, más y más original o más y más innovador. Ciertamente estas metas pueden conseguirse gracias a procesos estandarizados, clichés que ordenan modos de pensar y organizar las ideas, para así, ofrecer unos resultados fruto de un proceso denominado creativo. 
En este sentido, se puede considerar un individuo como creativo en tanto que sobresale en seis cuestiones: estética, descubrimiento de problemas, movilidad, trabajar al límite de la propia capacidad, objetividad y motivación intrínseca. $^{5}$

En lo que se refiere al primer apartado, el de estética parte de que las personas creativas se decantan por principios estéticos, movidos por la búsqueda permanente de la belleza y la perfección buscando infatigablemente la elegancia, la originalidad. Es una constante superación de lo anterior fundamentada en la constante investigación que aporte mayor conocimiento y amplíe los horizontes de conocimiento.

En cuanto al segundo apartado, el descubrimiento de problemas, se fundamenta en la atención hacia la resolución de los problemas.

La movilidad como la capacidad de cambiar de pensamiento, de idea, de perspectiva. La extraordinaria capacidad de planteamiento abstracto. El creativo disloca su personalidad y se sale de sí, para ponerse en la piel del espectador, lector, etc.

El cuarto punto, el trabajo al límite de la propia capacidad, considerando lo que aparentemente es imposible como un reto que ofrece una nueva oportunidad para desafiar su capacidad.

En cuanto al quinto apartado, la objetividad, debe ser entendida como la atención exagerada sobre ciertos aspectos que para la gente común pasan de un modo desapercibido, no prestando interés alguno. En cambio, la mente creativa, se detiene en aspectos concretos, detalles que definen y aportan características relevantes de hechos mayores, atienden a juicios y argumentos selectos que definen su forma de ser.

\footnotetext{
${ }^{5}$ PERKINS, D.N.: “Creativity by desing”, Educational Leadership, 42, pp. 18-25.
} 
El último punto alude a la motivación intrínseca, relacionada con la concepción de la realidad y cómo organizan su propia concepción de la misma, y su labor en ella.

De este modo, atender a la creatividad de Gustave Doré desde estos presupuestos nos resulta al menos justo, ya que permite apreciar una serie de consideraciones en cuanto a su genialidad en lo que se refiere a su estética, sus motivaciones, su capacidad de trabajo infatigable, su interés por la objetividad representativa y su fidelidad arqueológica, así como su enorme flexibilidad para adaptarse a situaciones de trabajo muy diferentes sabiendo conseguir siempre un alto grado de calidad y una belleza indudable capaz de mostrar los sentimientos más sublimes, trágicos, nobles y heroicos de la humanidad.

Doré como artista practicó diferentes géneros como la pintura o la escultura, aunque fue en la ilustración gráfica donde destacó por encima de todo.

$\mathrm{Su}$ ingente producción asombra sobre todo cuando consideramos que vivió cincuenta y un años. Así, hizo unos cuatrocientos oleos, unas docenas de esculturas, la más famosa la de Alejandro Dumas, en París. Pero la sorpresa viene con sus más de diez mil grabados.

Doré nació en enero de 1832 en Estrasburgo y su afición por el dibujo fue bien temprana, aunque no recibió ninguna formación académica poseía una enorme destreza y un gran virtuosismo. Como considera Dan Malan a la edad de doce años se hizo su propia piedra litográfica con la que hacia colecciones de grabados e historias. Cuando contaba con quince años viajó hasta París, era la primera vez que viajaba su familia hasta la capital francesa y él se enamoró de la belleza de la ciudad. Paseando descubrió una editorial con series de grabados fijados en la ventana y le sedujo la idea de trabajar allí. Así que pensó ir al día siguiente. Tal era su interés que al día siguiente fingió estar enfermo para no acompañar a su familia, sin embargo, marcho a la editorial con una serie de dibujos y se presentó ante el editor, Charles Philipon. Él, Doré, puso los dibujos sobre su mesa y Philipon sorprendido e impresionado por el estilo 
estéticamente antiguo llamó asombrado a las demás personas de la oficina. No se podía creer que un niño de quince años pudiera haber alcanzado tal perfección, y le ofreció un lucrativo contrato que hizo que con sólo dieciséis años fuese el ilustrador mejor pagado de Francia.

Como ilustrador usó las técnicas de la litografía, que en esos momentos estaba en plena ebullición, pero la que más fama le reportó fue la xilografía, que seguía la línea iniciada por T. Bewick a finales del siglo XVIII, es decir, la xilografía a la testa, donde se grababa en sentido de la veta de la madera y permitía una mayor perfección y precisión, además que al obtener la plancha, el taco, este se obtiene de mayor tamaño, lo que permite crear estampas de mayores dimensiones, acordes a las páginas de los libros. Por otro lado, la madera tampoco era como antes, ya que el enorme desarrollo del comercio posibilitó la importación de maderas exóticas que ofrecían mayor dureza y resistencia ante la prensa, con lo cual se obtenían series más grandes.

Es interesante como se considera la ilustración gráfica, como creatividad o acto creativo, en estos momentos, ya que en el proceso editorial participan diferentes personas: editores, autores, ilustradores, etc. Pero el ilustrador puede cumplir la función de autor como es el caso de nuestro autor con su primera obra, Los Trabajos de Hércules (1847) para la que hizo el texto, las imágenes, incluso realizó las piedras litográficas. Aunque posteriormente llegaría a ser artista creador una figura que surge en este siglo, que propone el dibujo y designa directrices a grabadores especializados, colaboradores en definitiva, quienes a diferencia de otros grabadores disponían de libertad interpretativa frente a la reproducción facsimilar.

Los rasgos que definen al ilustrador es su capacidad para proporcionar una imagen adecuada y creíble a la escena ilustrada, captando la esencia de la historia, además de no perder el rasgo semántico que lo vincula al texto. En este sentido no se debe perder el referente ni a los elementos narrativos, ni al propio contexto en el que la obra originariamente fue realizada. Así, el hecho de que Doré prefiriese la xilografía está relacionado con el hecho de que sus obras ilustradas son básicamente clásicos de la literatura como El Quijote, La 
Divina Comedia, El Paraíso Perdido, La Biblia, etc. Con lo cual otorga una gran adecuación entre el texto y la imagen, consiguiendo un equilibrio estético entre ambos códigos que permite en palabras de Moles generar un discurso bimedia que facilita la comprensión y el embellecimiento por la función representativa de ambos sistemas.

Así, Doré resuelve de modo adecuado, original y personal sus diferentes ilustraciones dando forma a grandes protagonistas de la Literatura universal y creando y/o usando tipos iconográficos que perduran en la actualidad.

Como podemos ver, la vida de Doré desde sus inicios destaca favorablemente, es un individuo inquieto y muy activo con actitudes propias para la experimentación y la resolución de problemas, aún sin medios como la construcción de la piedra litográfica con doce años. Además de su enorme capacidad de trabajo que ante ingente producción es de suponer que en más de una ocasión se encontraría caminando por los bordes del límite. Además poseía una motivación intrínseca como su predisposición a ilustrarlo todo, lo que le condujo hasta Philipon y a llegar a las cotas que llegó.

Por otro lado, su actividad, su enorme curiosidad le llevo a viajar por casi toda Europa, Pirineos, Alpes, Escocia, incluso recorrió España, la cual ilustró para la obra de Davillier: Viaje por España (1874) donde ofrece una visón romántica no sólo del paisaje, aunque fiel a la realidad, sino también ofrece una visión de los tipos o personajes, que recorrían el país. En este sentido ofrece arquetipos populares como bandoleros, bailarinas aragonesas, malagueñas, etc.

Como se puede apreciar Doré pretendía ilustrarlo todo, a diferencias de otros autores que se centraban más en un estilo determinado. Así, Doré, cambiaba de registro de un modo increíble, ya que no podemos seguir una línea evolutiva en lo que refiere a su evolución estilística, sino únicamente a su evolución cronológica. Esto es así, porque dominaba muy distintos recursos y todos los realizaba con total dominio. Pasaba por la caricatura, lo épico, el 
sarcasmo, la crónica social, lo fabuloso o lo sublime. Por tanto es como si se moviera en varias direcciones, además de practicar el romanticismo, el eclecticismo, incluso recurre a motivos premodernistas y simbolistas, como se puede apreciar en las ilustraciones que realizó para los poemas de E. A. Poe The Raven (1883) oníricos y neorrománticos.

Doré se alejó de la tendencia popular y gracias a su calidad se aproximó a la high cult, canalizando la imagen culta y ofreciéndoles personajes con identidad y forma concreta.

Hemos estado ofreciendo unos apuntes biográficos que permiten apreciar las cualidades que definían a nuestro artista como una persona creativa. Así, hemos apreciado su alta capacidad inventiva y su facilidad para adaptarse y ofrecer soluciones diferentes, pero originales para las distintas historias.

Lo más destacable es quizás su capacidad para captar lo sublime, que podríamos definir como la sobrehumana grandeza que hace al héroe romántico por excelencia. El héroe que supera y sobrepasa el miedo del exceso y se enfrenta a él, desconociendo si saldrá victorioso, pero ya ganador ante dicha hazaña. Así, el individuo consciente de sus limitaciones, no se acobarda, sino al contrario, se esfuerza para superarlo.

Estas pasiones y emociones recorren la obra de Doré. Por ello ofrece un mundo glorioso plagado de grandeza y heroísmo, donde el hombre se pone a la altura de dios gracias a su actitud valiente, en un mundo unas veces lírico y otras terrible, pero siempre poético.

Todo esto se aprecia en sus diferentes obras fundamentalmente en el Paraíso Perdido de John Milton, donde nos presenta a un Satán, ángel recién expulsado del Paraíso, casi humano, de belleza apolínea y asustado que no sabe hacia donde ir para afrontar su destino abigarrado al precipicio en rocas de tremenda melancolía. 
Del mismo modo en El Quijote nos presenta a un visionario obseso con lo heroico capaz de luchar ante los monstruos más terribles superando toda clase de temores, prejuicios y engaños que la sociedad puede ofrecer. Es a Doré a quién debemos el modelo iconográfico que del Quijote poseemos, como un personaje de triste figura, ya que aunque así lo define Cervantes, en ilustraciones anteriores no es presentado como tal, sino como un caballero tradicional con semblante serio y riguroso. En cambio Doré capta la esencia del personaje cervantino, su carácter idealista y heroico, puesto que es el Romanticismo el que dotará de nuevo significado a este personaje. Anteriormente se asociaba al Quijote con una serie de cuentos cómicos ${ }^{6}$, mientras que ahora se carga de dramatismo y tristeza. No obstante era el Quijote, Alonso Quijano, la esencia misma del movimiento romántico, amante de lo medieval, fantasioso y lleno de valores, el mismo personaje que mostró Doré en sus ilustraciones, mientras otros se limitaron a presentarlo como un loco, como la pintura de R. P. Bonington de 1825 Don Quijote en su estudio; o la litografia de H. Daumier de 1865 Don Quijote y Sancho Panza que nos lo presenta en su cadavérica grandeza.

También aparece lo sublime en La Divina Comedia y en La Biblia. En esta última gracias a la enorme capacidad de expresión del infinito en sus paisajes, de tremendo realismo, pero a su vez cargados de lirismo y artificio, el cual viene dado por sus composiciones de gran teatralidad, lo que confiere un sentido de orden que exalta la belleza por los equilibrios, las armonías, las simetrías y el magnífico uso de la escala y la proporción capaz de crear esos efectos de profundidades que no acaban, además de los fabulosos contrastes que activan el dinamismo de la escena y del espacio.

En todas ellas capta la gran diferencia entre lo finito y lo infinito. Así, sus personajes, presentados con perfiles humanos, incluso cuando son demonios, reflejan humanidad, presentándose como la esencia misma de la finitud, de la muerte, en contraste con el carácter infinito de la Naturaleza que sobrepasa los límites del hombre y que es presentada con profundos horizontes,

\footnotetext{
${ }^{6}$ HONOUR, H.: El Romanticismo. Alianza, Madrid, 1992.
} 
que ofrecen paisajes bucólicos cargados de lirismo y belleza por el juego de las luces que tamizan o remarcan el espacio y el tiempo.

Doré nos ofrece un mundo plagado de nostalgia, construye un mundo artificial y nuevo, con un alto componente fantástico y fabuloso. Ofrece una vuelta al pasado, a un mundo mítico, el de la Literatura, con el que pretendía crear una nueva humanidad.

La grandeza de Doré es su estilo, su maniera. Así, es su increíble dominio del dibujo y sus composiciones las que identifican su virtuosismo, sobretodo para establecer ese juego semántico entre el texto y la imagen. Sus líneas sólo son rectas en el infinito horizonte, las formas y figuras se deben a líneas y arabescos que generan pliegues, tensiones, ritmos y volúmenes. Las líneas forman contornos que se retuercen, con líneas rotas y vibrantes de pura influencia miguelangelesca, que carga a las figuras de esa terribilità propia del artista manierista.

Sus tipos iconográficos son tremendamente clásicos, aunque, como he dicho, la influencia de Miguel Ángel es muy grande. Tremendas líneas sinuosas, las cuales quiebran figuras de enormes músculos hinchados que se contorsionan, sobre todo, en espacios aéreos, como sus torbellinos de ángeles o sus visiones del Infierno dantesco que recuerdan a la Capilla Sixtina.

Pero quizás una de las mejores muestras de su creatividad se encuentra en las ilustraciones que realizó para la Historia de la Santa Rusia (1854), donde nos presenta una gran capacidad innovadora a la hora de contarnos la historia, ya que se vale de recursos que anticipan la abstracción y el simbolismo, jugando para ello con los conceptos y eludiendo en muchos casos cualquier pretensión de representación con algún referente real, más que la propia idea, el propio concepto.

En este sentido, Doré, cambia las convenciones narrativas propias de la representación pictórica y nos muestra un tintero que derrama su tinta sobre el papel, manchando la pluma y el texto. La tinta se corre ascendiendo en manchas verticales, ocultando los renglones y desmontando las letras que se 
derrumban en la oscuridad de la mancha. Pero es más adelante, donde consigue alcanzar el mayor grado de abstracción y el abandono total de la representación, ya que muestra una enorme mancha roja que se expande por el papel, símbolo de la tragedia que cuenta el libro; así como otra ilustración, que para representar la oscuridad de un pasaje cubre totalmente el espacio de representación de negro.

Destacar también que la Historia de la Santa Rusia está presentada como si fuera un cómic, es decir, intercalando texto e imagen. Pero las ilustraciones en la mayoría de los casos ocupan bandas longitudinales continuadas por un pequeño párrafo y otra imagen, que por articulación generan el transcurso del tiempo. Por otro lado, usa lo cómico-burlesco acercándose a lo grotesco, influenciado de su trabajo en el Journal pour Rire. Por ello, se puede considerar a Doré como uno de los iniciadores del género del cómic, además para que quede más patente presenta tres bandes desine donde presenta tres pentagramas musicales y en su interior reduce las notas a signos gráficos que reproducen un desfile militar cargado de ritmo y movimiento.

Hasta aquí hemos intentado conceptualizar la creatividad, así como desarrollarla un poco, además de ofrecer una visión de este artista desde unos presupuestos que fundamentasen su creatividad y sus esfuerzos por ofrecer una visión nueva del mundo a través de sus obras que ilustran las obras de otros autores. Es quizás por esto el que el nombre de Gustave Doré, no tenga la consideración que se merece, dada su genialidad. 


\section{Bibliografía.}

BAÑos GONZALEZ, M.: Métodos Heurísticos y Creación Publicitaria (Tesis

doctoral, dirigida por el Dr. D. Francisco García García). Universidad Complutense de Madrid, Madrid,1999.

BUERO VALLEJO, A.: Gustave Doré. Estudio critico-biográfico. 1949; en Obra Completa. Planeta, Madrid, 1999.

ESTEVE BOTEY, F.: El grabado en la ilustración del libro. CSIC, Madrid, 1948. ESTRADA HERRERO, D.: Estética. Herder, Barcelona, 1988.

GERVILLA, A.: Creatividad, inteligencia y rendimiento. Universidad de Málaga, Málaga, 1978.

HONOUR, H.: El Romanticismo. Alianza, Madrid, 1992.

MOLES, A.: La Imagen. Editorial Trillas, México, 1991.

ROSEMBLUM, R. y JANSON, H. W. : El Arte del siglo XIX. Akal, Madrid, 1992.

SCHILLER, F.: Lo Sublime. (De lo Sublime y Sobre lo Sublime). Hybris-Ágora, Málaga, 1992. 